\title{
REVIEWS
}

Agnieszka Beata Mielczarek ${ }^{1, A, D}$, F, Tomasz Konopka ${ }^{2, \text { E, F, }}$ EWA IWANICKA-GRZEGOREK ${ }^{1, B, C}$

\section{Anti-Erosion Properties of a Stabilized Stannous Fluoride Dentifrice}

\author{
Własności antyerozyjne past do zębów \\ ze stabilizowanym fluorkiem cyny \\ ${ }^{1}$ Department of Conservative Dentistry, Medical University of Warsaw, Warsaw, Poland \\ 2 Department of Periodontology, Wroclaw Medical University, Wrocław, Poland
}

A - research concept and design; $\mathbf{B}$ - collection and/or assembly of data; $\mathbf{C}$ - data analysis and interpretation;

$\mathbf{D}$ - writing the article; $\mathbf{E}$ - critical revision of the article; $\mathbf{F}$ - final approval of article

\begin{abstract}
Dental erosions are non-carious damages of hard dental tissues, resulting from their dissolution by the action of acids, whose presence in the oral cavity is not associated with the metabolic activity of cariogenic bacteria. Erosion losses are initiated on the enamel surface, and lack of control over their progress leads to the gradual destruction of dental tissues. The problem of the occurrence of dental erosion is increasingly present in the Polish population. An alarming intensification of this phenomenon can be found among adolescents and young adults. Due to the complex etiology of erosive lesions, new methods are sought to enhance the protective potential of dental tissues against erosive factors. New formulations of dentifrice with stannous fluoride stabilized with sodium hexametaphosphate are generating particular interest. The several years of presence of these products on the Polish market have provoked us to undertake studies evaluating their effectiveness in various areas of dental problems.

This paper reviews literature reports on the effect of $\mathrm{SnF}_{2}$-containing toothpastes in reducing the occurrence of erosive lesions. Results indicate that dentifrice with stabilized formula of fluoride, tin, and sodium hexametaphosphate (SHMP) is more effective in protecting the enamel from erosion when compared with toothpastes containing other fluoride compounds. Prolonged application of formulation included $\mathrm{SnF}_{2}$ gradually increase the dental tissue resistance to acid attack (Dent. Med. Probl. 2016, 53, 2, 268-272).
\end{abstract}

Key words: prevention, toothpaste, stannous fluoride, dental erosion.

Słowa kluczowe: zapobieganie, pasty do zębów, fluorek cyny, erozje zębów.

For many years the development of caries was considered to be the main oral pathology which manifests loss of dental tissues. However, the increased incidence of non-carious lesions, also leading to the destruction of enamel and dentine, has been observed recently [1]. Teeth display wear results from a co-existing triad of processes such as abrasion, attrition and erosion [2]. On the one hand, its presence may be recognized as a physiological phenomenon that naturally comes with age, and its intensity is related to the function of the whole stomatognathic system. On the other, a worrying feature is the occurrence of erosive le- sions among other, less typical age groups, namely adolescents and young adults [3-5]. According to global epidemiological data, enamel erosion occurs in about half of teenagers, while in Australia and Greece the problem concerns almost $80 \%$ of the population. In the Polish population, erosive lesions are diagnosed in about $25 \%$ of 15 -year-olds and $42 \%$ of 18 -year-olds [6, 7].

Erosion is defined as surface dissolution of hard dental tissues under the influence of acids whose presence in the oral cavity is not related to bacterial metabolism [8]. In recent years, the availability and consumption of acidic beverages like 
soft, energizing and isotonic drinks has risen. Paradoxically, promoted healthy lifestyle, diet rich in fresh fruit and fruit drinks, wholegrain products, as well as physical exertion leading to dehydration and diminished protective action of saliva, all contribute to the development of non-carious lesions in hard dental tissues [9-11]. Other factors like chronic stress, mental illness, alimentary diseases leading to the presence of gastric secretion in the mouth and subsequent lowering of oral $\mathrm{pH}$ are also contributory $[12,13]$. The 2015 paper Effect of endurance training on dental erosion, caries and saliva introduces the term "sports dentistry", which indicates the scale of the problem of sportsrelated dental erosion in patients who train intensively and are temporarily dehydrated [14].

Effective methods of preventing the loss of hard dental tissues have been sought for years. In the case of dental caries, the importance of fluoride in its prevention and treatment has been well documented. The regular use of fluoridated toothpaste contributes to the reduction of the incidence of caries in many populations, with fluoride supplementation playing a vital role in the course of early carious lesions. Due to the sub-surface nature of white spot lesions, there is still a chance to implement a non-invasive therapeutic protocol of remineralization of potential damage $[15,16]$.

In the case of erosive lesions, the destructive process is initiated on the enamel surface and leads to the gradual loss of its subsequent layers without any means of their repair. It is, therefore, important to implement prophylactic procedures that would protect enamel structure from erosive factors.

Saliva plays a key role in dental erosion prevention. As a result of selective adsorption of salivary proteins a semipermeable membrane is formed on the enamel surface, known as acquired dental pellicle. This structure consists of 130 proteins, i.e., $\mathrm{Ca}$ - and P-binding proteins, proline rich proteins, histatins and statherines. Its presence can build the natural barrier, which partially inhibits the diffusion of $\mathrm{H}^{+}$ions and dental enamel dissolution. Pellicle created under natural conditions has higher preventive potential. Improvement of the saliva and pellicle protective properties by application of prophylactic products is the important purpose of erosion prevention [17-19].

With respect to erosion, toothpaste seems to be also the optimal medium for delivering active agents for dental tissues protection. In recent years, new formula of dentifrice with stabilized stannous fluoride has been launched on the market. It is not a new solution, because stannous fluoride was the first compound to have been added to the so-called therapeutic toothpastes in 1950s in the USA $[20,21]$. Their composition at that time was insufficient and dramatically reduced bioavailability of both fluoride and tin, and thus effectiveness of such formula was limited. Stannous fluoride is unstable in its aqueous solution and $\mathrm{pH}$ higher than 4 since it undergoes oxidation and hydrolysis resulting in inactive forms of tin and precipitates. The preventive potential of stannous fluoride has prompted more research on a new formula for this chemical compound. Attempts were made to reduce the content of water in dentifrice and use tin stabilizers such as pyrophosphates, gluconates, copolymers or stannous chloride. Eventually, the preparation of a stannous fluoride-sodium hexametaphosphate complex made it possible to increase its bioavailability in the mouth and facilitate its properties more effectively. It has been demonstrated that sodium hexametaphosphate has the ability to combine with the pellicle, and its several-hour retention increases its protective, anti-erosive potential. Buscher et al. [22] confirmed the ability of phosphate groups of hexametaphosphate polymer to combine with free calcium ions on the enamel surface.

Years of experiments came to fruition in 2005 when toothpastes containing stabilized stannous fluoride were launched on the American market [23]. Since 2010, toothpastes with this advanced formula have been available in Poland as well. In accordance with European guidelines, the original formula of toothpastes containing $1110 \mathrm{ppm}$ of fluoride as $\mathrm{SnF}_{2}$ has been supplemented with $350 \mathrm{ppm}$ of $\mathrm{F}$ in the form of $\mathrm{NaF}$ in order to optimize the fluoride content as active ingredient.

A few years after the appearance of new $\mathrm{SnF}_{2}$ dentifrice formulation on the market, an attempt was made to evaluate their enamel protective role against erosive factors in relation to other formulations of available toothpastes. The aim of this paper is to present the results of related investigations.

Available results are primarily based on in $v i$ tro and in situ studies since laboratory conditions create a possibility to utilize several advanced techniques such as SEM, OCT, CLSM, QLF, AFM and USG to assess the condition of hard dental tissues. However, the most commonly used method is the one which examines the profile of enamel surface, its microhardness, and also evaluates the degree of enamel loss in relation to a reference surface by means of transverse microradiography (TMR) [24].

The most interesting issue was to estimate the effectiveness of dentifrices containing $\mathrm{SnF}_{2}$ in relation to other available toothpastes formulas. One of the comparative studies was undertaken to examine the protective effect of stannous flu- 
oride toothpaste and sodium fluoride toothpaste on enamel previously exposed to orange juice. The measurements of the depth of created erosive lesions were based on prophylometric study. The obtained results unequivocally indicate that $\mathrm{SnF}_{2}$-containing dentifrice is more effective in protecting the enamel surface against acid attack than NaF-containing toothpastes [25].

Baig et al. [26] evaluated the effect of $\mathrm{SnF}_{2}$ on inhibiting hydroxyapatite (HAP) solubility. In their experiment, powdered HAP was initially subjected to the effect of sodium fluoride $(\mathrm{NaF})$, stannous fluoride $\left(\mathrm{SnF}_{2}\right)$ or water, and then HAP was exposed to acids in laboratory conditions. The results indicated that in comparison with water, $\mathrm{SnF}_{2}$-containing formulae were more effective in inhibiting HAP solubility in acids (92.8\%) than NaF-based preparations (61.3\%).

The experiments of Faller et al. [27] have been undertaken to continue establishing the ability of dentifrices containing various fluoride compounds to protect enamel against erosive challenge. The authors compared the preventive potential of 1100 ppm F in $\mathrm{SnF}_{2}, 1100$ ppm F in $\mathrm{NaF}$ and $1100 \mathrm{ppm} \mathrm{F}$ as sodium monofluorophosphate (SMFP). The mean enamel loss was estimated for all experimental groups. The results indicated that the mean surface loss of the enamel treated with $\mathrm{SnF}_{2}$-containing toothpaste was significantly lower $(10.3 \mu \mathrm{m}$ for the citric acid and $2.0 \mu \mathrm{m}$ for the phosphoric acid) in comparison with enamel samples that were treated with NaF-containing paste (24.5 $\mu \mathrm{m}$ and $12.8 \mu \mathrm{m}$, respectively) and SMFPcontaining paste ( $28 \mu \mathrm{m}$ and $14.9 \mu \mathrm{m}$, respectively).

A continuation of studies by Faller et al. [28] concerned the evaluation of twelve selected dentifrices available on the market, containing different compounds of fluoride. The comparative analysis took into account the anti-erosive properties of original $\mathrm{SnF}_{2}$ toothpaste containing $1100 \mathrm{ppm} \mathrm{F}$, and its European version, supplemented additionally with sodium fluoride. The preliminary application of selected dentifrice on surfaces of enamel samples was conducted in twenty 2-minute cycles. After that, the erosive attack was induced by $1 \%$ citric acid with $\mathrm{pH}$ of 2.3 . The results of the study showed that maximum erosive protection of enamel was obtained after the application of both $\mathrm{SnF}_{2}$-containing formulations, and their level of protection was comparable.

A similar comparative in vitro experiment was conducted by Eversole et al. [29], in which new formulations of toothpaste with $8 \%$ arginine bicarbonate and dentifrice with stannous fluoride were included. The authors assessed the effect of toothpaste containing $1100 \mathrm{ppm} \mathrm{F}$ as $\mathrm{SnF}_{2}$, 1100 ppm F as NaF, 1450 ppm F as SMFP and NaF, and $1450 \mathrm{ppm}$ F as SMFP with $8 \%$ arginine bicarbonate added to protect enamel exposed to $1 \%$ citric acid. The results of these in vitro study confirmed the highest efficacy of stannous fluoride in erosion prevention.

In situ experiments constitute another group of reports on the benefits of $\mathrm{SnF}_{2}$-containing dentifrice. These kinds of studies are very important for the validation of the results obtained in in vitro experiments. In most of the related studies, during the first stage of the investigation enamel samples with erosive lesions, induced in vitro or in vivo, undergo natural processes occurring in the mouth, including absorption of acquired pellicle, $\mathrm{pH}$ fluctuations, and the effect of oral hygiene products. Subsequently, quantitative and qualitative laboratory evaluation of the condition of enamel specimens was conducted.

Using in situ experiments, an attempt was made to assess the anti-erosive potential of $\mathrm{SnF}_{2}$ and NaF-containing dentifrices as well as those with $\mathrm{NaF}$ and potassium nitrate. After fifteen days of erosive cycling process, it was observed that in the $\mathrm{SnF}_{2}$-protected samples enamel loss was $38 \%$ lower than in other groups [30]. Bellamy et al. [31] confirmed in their in situ investigation a higher preventive potential of $\mathrm{SnF}_{2}$-containing dentifrice than the NaF-containing one. The exposure of enamel sample to 300-minute attack of citric acid resulted in a $86.9 \%$ lower level of enamel loss in samples previously subjected to the action of $\mathrm{SnF}_{2}{ }^{-}$ containing dentifrice than in samples treated with sodium fluoride toothpastes.

In situ investigation of Huysmans et al. [32], in which two $\mathrm{SnF}_{2}$-containing dentifrices were estimated, reduction of enamel loss was registered on a $26-37 \%$ level.

The present data concerning the efficacy of various fluoride dentifrices in erosion protection clearly shows that formulas with stabilized stannous fluoride are more effective in reducing the erosive enamel dissolution than other marked products with the same type and amount of active ingredients. The ability of stannous fluoride to adhere to the enamel surface allows for the formation of an acid-resistant barrier, which provides better enamel protection against acid attack. The recently published Consensus Report of the European Federation of Conservative Dentistry unequivocally confirms that dentifrices containing stannous fluoride have a great potential for inhibiting erosion progression [33].

In conclusion, stabilized compound of tin and fluoride modifies the pellicle structure and increases its preventive potential. In contact with enamel, stannous fluoride and sodium hexametaphosphate form a complex protective barrier, 
which is resistant to acid attack. Long-term application of dentifrice with stannous fluoride gradually increases the resistance of dental tissues to the action of acids. Toothpastes with stabilized stan- nous fluoride and sodium hexametaphosphate are more effective in protecting the enamel against erosion than dentifrices containing other fluoride compounds.

\section{References}

[1] Johansson A.K., Omar R., Carlsson G.E., Johansson A.: Dental erosion and its growing importance in clinical practice: from past to present. Inter. J. Dent. 2012, Article ID 632907.

[2] Addy M., Shellis, R.P.: Interaction between attrition, abrasion and erosion in tooth wear. Monogr. Oral Sci. 2006, $20,17-31$.

[3] Mantonanaki M., Koletsi-Kounari H., Mamai-Homata E., Papaioannou W.: Dental erosion prevalence and associated risk indicators among preschool children in Athens, Greece. Clin. Oral Invest. 2013, 17, 585-593.

[4] Jaeggi T., Lussi A.: Prevalence, incidence and distribution of erosion. In: Erosive tooth wear - from diagnosis to therapy. Monographs in Oral Science Karger. Eds.: Lussi A., Ganss C. Basel, 2014, 25, 55-73.

[5] Bartlett D., Lussi A., West N., Bouchard P., Sanz M., Bourgeois D.: Prevalence of tooth wear on buccal and lingual surfaces and possible risk factors in young European adults. J. Dent. 2013, 41, 1007-1013.

[6] Wierzbicka M., Szatko F., Strużycka I., Rusyan E., Ganowicz M., Zawadziński M., Garus-Pakowska A.: Stan zdrowia jamy ustnej i jego uwarunkowania oraz potrzeby profilaktyczno-lecznicze dzieci wieku 5, 7, 15 lat. Monitoring Zdrowia Jamy Ustnej 2011.

[7] Strużycka I., Rusyan E., BogusŁawska-KapaŁa A.: Prevalence of dental erosion in young adults aged 18 years in Poland. Przegl. Epidemiol. 2015, 68, 689-693.

[8] Ganss C.: Definition of erosion and links to tooth wear. Monogr. Oral Sci. 2006, 20, 9-16.

[9] Bartlett D.W.: The role of erosion in tooth wear: etiology, prevention and management. Int. Dent. J. 2005, 55, 277-284.

[10] Gurgel C.V., Rios D., De Oliveira T.M., Tessarolli V., Carvalho F.P.: A multifactorial analysis of factors associated with dental erosion. Int. J. Paediatr. Dent. 2011, 21, 50-57.

[11] Barbour M.E., Lussi A.: Erosion in relation to nutrition and the environment. Monogr. Oral Sci. 2014, 25, $143-154$.

[12] Ranjitkar S., Kaidonis J.A., Smales R.J.: Gastroesophageal reflux disease and tooth erosion. Inter. J. Dent. 2012, 479850.

[13] Meshramkar R., Lekha K., Nadlger R.: Tooth wear, etiology, diagnosis and its management in elderly: a literature review. Inter. J. Prosth. Rest. Dent. 2012, 2, 38-41.

[14] Frese C., Frese F., Kuhlmann S., Saure D., Reljic D., Staehle H.J., Wolff D.: Effect of endurance training on dental erosion, caries, and saliva. Scand. J. Med. Sci. Sport 2015, 25, e319-326.

[15] Cury J.A., Tenuta L.M.: Enamel remineralization: controlling the caries disease or treating early caries lesions? Braz. Oral Res. 2009, 23, Suppl. 1, 23-30.

[16] Tenuta L.M., Cury J.A.: Laboratory and human studies to estimate anticaries efficacy of fluoride toothpastes. Monogr. Oral Sci. 2013, 23,108-124.

[17] Cheaib Z., Lussi A.: Impact of acquired enamel pellicle modification on initial dental erosion. Caries Res. 2011, $45,107-112$.

[18] Hara A.T., Ando M., Gonzalez-Cabezas C., Cury J.A., Serra M.C., Zero D.T.: Protective effect of the dental pellicle against erosive challenges in situ. J. Dent. Res. 2006, 85, 612-616.

[19] Hannig M., Hannig C.: The pellicle and erosion. Monogr. Oral Sci. 2014, 25, 206-214.

[20] Muhler J.C., Radike A.W., Nebergall W.H., Day H.G.: The effect of a stannous fluoride-containing dentifrice on caries reduction in children. J. Dent. Res. 1954, 33, 606-612.

[21] Muhler J.C., Radike A.W.: Effect of a dentifrice containing stannous fluoride on dental caries in adults. II. Results at the end of two years of unsupervised use. J. Am. Dent. Assoc. 1957, 55, 196-198.

[22] Busscher H., White D., van Der Mei H., Baig A., KozaK K.: Hexametaphosphate effects on tooth surface conditioning film chemistry - in vitro and in vivo studies. J. Clin. Dent. 2002, 13, 38-43.

[23] White D.J.: A "return" to stannous fluoride dentifrices. J. Clin. Dent. 1995, 6, 29-36.

[24] Attin T., Wegehaupt F.J.: Methods of assessment of dental erosion. Monogr. Oral Sci. 2014, 25, 123-142.

[25] Hooper S.M., Newcombe R.G., Faller R., Eversole S., Addy M., West N.X.: The protective effects of toothpaste against erosion by orange juice: studies in situ and in vitro. J. Dent. 2007, 35, 476-481.

[26] Baig A.A., Faller R.V., Yan J., Ji N., Lawless M., Eversole S.L.: Protective effects of SnF 2 - Part I. Mineral solubilisation studies on powdered apatite. Inter. Dent. J. 2014, 64, Suppl 1, 4-10.

[27] Faller R.V., Eversole S.L., Tzeghai G.E.: Enamel protection: a comparison of marketed dentifrice performance against dental erosion. Am. J. Dent. 2011, 24, 205-210.

[28] Faller R.V., Eversole S.L., Saunders-Burkhardt K.: Protective benefits of a stabilized stannous-containing fluoride dentifrice against erosive acid damage. Int. Dent. J. 2014, 64, Suppl. 1, 29-34.

[29] Eversole S.L., Saunders-Burkhardt K., Faller R.V.: Erosion protection comparison of stabilised $\mathrm{SnF}_{2}$, mixed fluoride active and SMFP/arginine-containing dentifrices. Int. Dent. J. 2014, 64, Suppl. 1, 22-28.

[30] Hooper S., Seong J., Macdonald E., Claydon N., Hellin N., Barker M.L., He T., West N.X.: A randomised in situ trial, measuring the anti-erosive properties of a stannous-containing sodium fluoride dentifrice compared with a sodium fluoride/potassium nitrate dentifrice. Int. Dent. J. 2014, 64, Suppl. 1, 35-42. 
[31] Bellamy P.G., Harris R., Date R.F., Mussett A.J., Manley A., Barker M.L., Hellin N., West N.X.: In situ clinical evaluation of a stabilized, stannous fluoride dentifrice. Int. Dent. J. 2014, 64, Suppl 1, 43-50.

[32] Huysmans M.C., Jager D.H., Ruben J.L., Unk D.E., Klijn C.P., Vieira A.M.: Reduction of erosive wear in situ by stannous fluoride containing toothpaste. Caries Res. 2011, 45, 518-523.

[33] Carvalho T.S., Colon P., Ganss C., Huysmans M.C., Lussi A., Schlueter N., Schmalz G., Shellis R.P., Tveit A.B., Wiegand A.: Consensus report of the European Federation of Conservative Dentistry: erosive tooth wear - diagnosis and management. Clin. Oral Invest. 2015, 19, 1557-1561.

\section{Address for correspondence:}

Agnieszka Mielczarek

Department of Conservative Dentistry

Medical University of Warsaw

Miodowa 18

00-246 Warsaw

Poland

E-mail: agnieszka.mielczarek@wum.edu.pl

Conflict of Interest: None declared

Received: 11.01.2016

Revised: 5.02.2016

Accepted: 18.02.2016 